\title{
PRACTICE OF YOGA IN PATIENTS WITH DIABETIC PERIPHERAL NEUROPATHY ATTENDING A TERTIARY CARE HOSPITAL IN NORTHERN INDIA: IMPLICATIONS DURING CORONAVIRUS DISEASE-19 PANDEMIC
}

\author{
SONIA MOR ${ }^{1 *}$, KARAN SINGH ${ }^{2}$, SUBHASH KUMAR WANGNOO³ ${ }^{3}$, TARUNIKA BAWA ${ }^{3}$, VIKAS DHIKAV ${ }^{4}$ \\ VARISHA ANJUM ${ }^{5}$
}

${ }^{1}$ Department of Pharmacy, Lingaya's Vidyapeeth, Faridabad and Indraprastha Apollo Hospitals, New Delhi, India. ${ }^{2}$ Department of Chemistry, Lingaya's Vidyapeeth, Faridabad, India. ${ }^{3}$ Consultant Endocrinologist and Diabetologist, Apollo Centre for Obesity, Diabetes and

Endocrinology, Indraprastha Apollo Hospitals, New Delhi, India. ${ }^{4}$ Department of Neurology, PGIMER and Dr RML Hospitals, New Delhi, India. ${ }^{5}$ Department of Pharmacy, School of Pharmaceutical Sciences, Lingaya's Vidyapeeth, Faridabad, India. Email: morsonia10@gmail.com

Received: 17 December 2020, Revised and Accepted: 21 January 2021

\section{ABSTRACT}

Objective: The objective of this study was to determine the prevalence of yoga practice in patients with Diabetic Peripheral Neuropathy (DPN) and to compare its acceptance among patients with chronic diseases other than DPN practicing non-yoga physical activities.

Methods: A pre-formed structured questionnaire-based cross-sectional study was conducted with a total of 98 out of 240 patients screened recruited during face to face structured interview, with a diagnosis of DPN. Data on the socio-demographics, age, duration of disease, glycemic controls (hemoglobin A1C [HBA1C] levels), and pain scores, numbness, and physical activity and other comorbid illnesses were collected.

Results: A total of 248 pre-diagnosed diabetic patients were screened; 98 study subjects (M: F=66:32) were enrolled with a mean age found to be 55.28 years. As diagnosed clinically and electrophysiologically, the prevalence of peripheral neuropathy was found to be $39.51 \%$. The mean pain score was 3.27. Risk factors for peripheral neuropathy included male sex, advanced age, higher body mass index (\%), higher $\mathrm{HbA1C}$ ( $\mathrm{n}=67.34 \%)$, having a sedentary lifestyle (38.77\%), overweight $(43,44.89 \%)$, and obesity $(21,21.42 \%)$ and $<40 \%$ belong to the diabetes of duration group of more than 10 years. A total of 16, male: 9 and female: 5 (22.85\%) out of 70 subjects were using yoga as physical activity in peripheral neuropathy group and of the control group (non-peripheral neuropathy group), only 8 (25\%) out of 25 were doing yoga. The overall proportions were compared using Chi-square, results were non-significant with $\mathrm{p}=-0.49$; Chi-square statistic -0.47 .

Conclusion: This implies that those with DPN are as likely to accept yoga as a physical activity compared to patients with other chronic illnesses practicing non-yoga physical activities.

Keywords: Peripheral neuropathy, Diabetes mellitus, Yoga.

(C) 2021 The Authors. Published by Innovare Academic Sciences Pvt Ltd. This is an open access article under the CC BY license (http://creativecommons.org/ licenses/by/4.0/) DOI: http://dx.doi.org/10.22159/ijas.2021v9i2.40542. Journal homepage: https://innovareacademics.in/journals/index.php/ijas

\section{INTRODUCTION}

Diabetes is the most common endocrinological disorder around the world leading to foot deformities such as infections, ulcers, pain, numbness, and/or dysaesthesia of the extremities [1]. An estimated $10 \%$ of Indians suffer from it. Dietary control and exercise are believed to be established treatment options in patients with Type II diabetes mellitus including other lifestyle disorders [4]. The most proximal behavioral cause of insulin resistance is physical inactivity [11] and it is considered to be one of the biggest public health problems worldwide [7]. It is believed that it can reduce the risk of diabetes and improve glucose tolerance [10] and enhances insulin sensitivity improves glycemic control [12].

On the contrary, it is found that lack of physical activity can increase the risk of diabetes by 3 times [5]. As per the World Health Organization, this situation is of significant concern because people living with noncommunicable diseases are at higher risk of severe coronavirus disease (COVID-19)-related illness and death [13].

Hence, it can be considered as a good alternative to exercise therapy [3,5]. In addition, it is believed that it can reduce medication use in adults with Type II Diabetes Mellitus [6]. In a regular busy modern lifestyle in urban areas, people go for use of various machines, less open space for exercise, it is difficult to adhere to dietary control and exercise as the management options in people with diabetes [4].
Psychological, neuroendocrinological, and immune mechanisms are involved in the beneficial effects of yoga on diabetes [4]. However, it has been shown in studies, Yoga practice may have significant use in the management and prevention of type 2 diabetes $[6,16]$.

Practicing yoga is a physical activity that can be done comfortably at home. Therefore, in light of the current evolving situation of COVID-19 pandemic, wherein outdoor activities are limited for diabetic patients due to their high risk for COVID-19 infection; Yoga should be preferred over other non-yoga physical activity in patients who have difficulty in walking due to joint problems, other forms of physical activity[8], for example, cycling-, swimming-, or gym-based activities.

Yoga, being an ancient discipline, comprises various practices/ Asanas such as, asanas, pranayama, mudras, capable to bring balance, weight loss and health benefits to the physical, mental, emotional, and spiritual dimensions of an individual. It offers significant positive clinical outcomes by reducing blood glucose levels and to help in the management of co-morbid conditions associated with type II diabetes mellitus $[4,5]$.

In the event of national lockdown being imposed in India with effect from 22 March 2020, scope of doing outdoor physical activities is severely restricted. Hence, a study was planned to know if yoga which is a popular complementary and alternative medicine in India and worldwide which could be done safely in the indoor environment, could 
be used as a substitute for doing outdoor physical activity. People who chose to do physical activities other than yoga walked on their rooftops house gardens or in front of their streets, or inside their housing societies.

\section{MATERIALS AND METHODS}

A pre-formed structured questionnaire-based cross-sectional study was conducted screened recruited during face to face structured interview, with a diagnosis of diabetic peripheral neuropathy (DPN). Data on the sociodemographics, age, duration of disease, glycemic controls (hemoglobin A1C [HBA1C] levels), and pain scores, numbness, and physical activity and other comorbid illnesses were collected. A detailed interview and follow-up for 3 months was done to know the acceptance of yoga and non-yoga physical activity in patients with DPN. Yoga group was practicing yoga on regular basis as Jogging and running at COVID time are restricted. There were no adverse reactions or discontinuation noted in yoga group.

In non-yoga groups, physical activities other than yoga such as home gym, cycling, and running. Reported reasons for not doing any physical activity by DPN were inability to walk, extreme pain in limbs, knee replacement surgeries, overweight, etc.

\section{Inclusion/exclusion criteria}

Patients fulfilling the inclusion criteria, above the age of 18 years and a minimum follow-up of 1 year, with a diagnosis of DPN with or without pain, were included. Neuropathy induced with other co-morbidities other than Type II diabetes mellitus were excluded from the study.

\section{Data collection}

The questionnaire was designed to explore patients' sociodemographic data, comorbidities, duration of the diabetes, duration of the peripheral neuropathy, pain scores (0-10), type and duration (in minutes) of physical activity (yoga or non-yoga), patient's perception about benefits of yoga complementary and alternative medicines (CAM) use before diagnosis, classification of CAM, types of CAM utilized, resources consulted, safety, and efficacy of CAM knowledge, attitude, and practice.

After evaluation by the investigator, patients were given pre-designed Pro forma (I). Demographic details, diagnosis, patients' history, and other details were noted (Case record form-Pro forma-I).

If there will be any history of CAM usage; then, Pro forma-II was administered to patients and details of the pattern of CAM usage, and satisfaction scores will be noted as well.

\section{Satisfaction score level using satisfaction with life scale (SWLS)}

SWLS is a free, seven-point Likert style response scale used for evaluation and assessment of a person's satisfaction with life to indicate the addressing areas of dissatisfaction, using five statements that you may agree or disagree with, using 1-7 scale, agreement with each item indicating the possible range of scores is 5-35 (scores 5-9 indicates extremely dissatisfied with life, whereas scores between 31 and 35 indicate that the respondent is extremely satisfied).

\section{Clinical safety measurements}

Height and weight of the subject were taken. Written medical records were examined to note diagnosis of the patients, regular follow- up medical reports such as $\mathrm{HbA} 1 \mathrm{C}$ values.

\section{Statistical calculations}

Statistical Package for the Social Sciences (SPSS) v. 19.0 was used to analyze the data collected from the study. The findings were described in terms of frequencies, percentages, means, and standard deviations.

The association between sociodemographic factors (gender, age, race, religion, educational background, occupation, family household income, and duration and control of diabetes) and CAM usage was determined using a Paired t-test and Chi-square test. The correlation was performed to determine association of pain scores (Likert scale) with age and physical activities.

\section{Regulatory and Ethical approval}

Ethical and scientific approval by the Institutional Ethics CommitteeClinical studies, Indraprastha Apollo Hospitals, New Delhi was taken from the institute as well as the site, before data collection in August 2019 (EC Application no.: IAH/ACAD-007-04-19).

Written and informed consent process was properly taken (Hindi and English) for enrolment in the study.

\section{RESULTS AND OBSERVATION}

A total of 248 pre-diagnosed diabetic patients were screened, 98 study subjects ( $\mathrm{M}$ : $\mathrm{F}=66: 32$ ) were enrolled with a mean age found to be 55.28 years. As diagnosed by clinically and electrophysiologically, the prevalence of peripheral neuropathy was found to be $39.51 \%$. The mean pain score was 3.27. Risk factors for peripheral neuropathy included male sex, advanced age, higher body mass index (\%), higher HbA1C ( $n=67.34 \%)$, having a sedentary lifestyle $(38.77 \%)$, overweight $(n=43,44.89 \%)$, and obesity $(n=21,21.42 \%)$ and $<40 \%$ belong to the diabetes of duration group of more than 10 years. The majority of participants $(n=55,56.12 \%)$ had underlying comorbidities listed as hypertension followed by dyslipidemia $(n=44,44.89 \%)$, thyroid $(n=18$, $18.36 \%)$, gastrointestinal problems $(n=14,14.28 \%)$, cardiovascular $(n=7,7.14 \%)$, and renal problems $(n=7,7.14 \%)$, respectively.

A total of 16 (22.85\%) out of 70 subjects were using yoga as physical activity in peripheral neuropathy group and of the control group (nonP.N. group); only 8 (25\%) out of 25 were doing yoga (Table 3 ). The overall proportions were compared using Chi-square, results were non-significant with $\mathrm{p}=-0.49$; Chi-square statistic -0.47 . A total of 28 $(28.57 \% /)$ out 98 recruited subjects were not doing any sort of physical activities, reasons given were inability to walk, knee replacements, and extreme pain while walking.

Comparison of time (minutes) in two groups, that is, yoga group versus non-yoga group

There was no statistical difference between the amounts of time, measured in minutes. Patients were able to do yoga or other non-yoga physical activities (47.81 \pm 21.13 ) versus (49.72 \pm 27.77 ) (Table 3 ), implying that compliance to yoga is as good as other non-yoga physical activity.

Although, doing physical activity may have aided in better glycemic controls of diabetic patients, comparative evaluation of pain scores of all three groups of doing yoga $(n=16)$, non-yoga $(n=54)$, and no physical activity $(n=28)$ groups made no difference in the pain scores.

To test the hypothesis that yoga is as good as other non -yoga physical activities in patients with peripheral neuropathy, pain scores of both the groups were compared using un-paired t-test at a level of significance of 0.05 . Total number of patients in yoga group $(n=16)$ and comparison group of 4 times of the number of patients $(n=54)$. This was additionally shown by no difference in pain scores of both the groups, respectively (3.31 vs. 3.37; $\mathrm{p}<0.05$ ) (Table 4).

\section{DISCUSSION}

In the present study, a total of $16(22.85 \%)$ out of 70 subjects were using yoga as physical activity in DPN group and of the control group (non-peripheral neuropathy group); only 8 (25\%) out of 25 were doing yoga. The overall proportions were compared using Chi-square, results were non-significant with $\mathrm{p}=-0.49$; Chi-square statistic -0.47 . The $\%$ of yoga is quite high in the present study, whereas it is slightly toward less the other studies, yoga as a CAM is practiced only in $8 \%$ [1], and yoga/ meditation together is practiced by $11.6 \%$ [2].

The present data depicted that lack of improvement in pain scores may be due to short duration of the study, that is, 12 weeks and longer 
duration study could bring better outcomes. This is because diabetes neuropathy is a chronic long-term debilitating condition, and it is quite possible that with longer duration of study and with large sample size for example, 6 months or 1 year could provide improvement in pain

Table 1: Demographic and clinical characteristics of participants $(\mathrm{n}=98)$

\begin{tabular}{|c|c|}
\hline Sociodemographic factors & Total, $n=98, \%$ \\
\hline \multicolumn{2}{|l|}{ Gender } \\
\hline Males & 67.34 \\
\hline Females & 32.65 \\
\hline \multicolumn{2}{|l|}{ BMI (body mass index) } \\
\hline Overweight (BMI>30) & 44.89 \\
\hline Obese $(\mathrm{BMI}<30)$ & 21.42 \\
\hline \multicolumn{2}{|l|}{ Treatments given } \\
\hline Oral & 53.08 \\
\hline Oral+Insulin & 44.89 \\
\hline Insulin & 1.02 \\
\hline \multicolumn{2}{|l|}{ Education level } \\
\hline No education & 8.16 \\
\hline Primary education & 32.65 \\
\hline Secondary education & 59.18 \\
\hline \multicolumn{2}{|l|}{ Occupation } \\
\hline Private sector & 10.20 \\
\hline Government sector & 6.12 \\
\hline Housewife & 27.5 \\
\hline Retired & 14.3 \\
\hline Business & 38.8 \\
\hline Agriculture & 3.1 \\
\hline \multicolumn{2}{|l|}{ Duration of diabetes mellitus } \\
\hline Below 1 year & 4.08 \\
\hline 1 year-10 year & 52.04 \\
\hline More than 10 years & 43.9 \\
\hline \multicolumn{2}{|c|}{ Duration of peripheral neuropathy } \\
\hline Below 1 year & 45.9 \\
\hline 1 year-10 year & 51.02 \\
\hline More than 10 years & 3.06 \\
\hline Uncontrolled HbA1C levels & 67.34 \\
\hline High blood pressure & 10.2 \\
\hline Numbness & 44.89 \\
\hline Smoking history & 16.32 \\
\hline Alcohol intake & 20.4 \\
\hline Urban Residence & 91.9 \\
\hline Physiotherapy & 27.56 \\
\hline
\end{tabular}

scores. This shows the similarity with the review that diet alone or physical activity alone compared to standard treatment influences the risk of type 2 diabetes mellitus (T2DM) [9] and especially its associated complications in people at increased risk of developing T2DM.

In a similar study (Schmid et al.), result indicating occupational therapy practitioners may consider adding yoga as a treatment intervention to address the needs of people with chronic pain and decrease depression [24].

In the present study, the patient had dyslipidemia (44.89\%) that comorbidity occurs very commonly in diabetic patients. A trial concluded that yoga lifestyle program designed specifically to manage diabetes helps in reducing the comorbidity of dyslipidemia in cases of patients with T2DM [14]

Another study revealed positive effects on functional balance in patients with DPN in a 6-week balance-based exercise training using the Interactive Video Game-Based system [15].

Similar results were seen in a study where yoga showed short-term outcomes among patients with diabetes type II, but not all of the improvements were statistically significant $[16,17]$. Acute and chronic improvements in insulin action on diabetes management were seen in with physical activity $[18,19]$.

In the present study, all the participants were overweight or obese, for whom standard western exercise or heavy physical exercise can be exhausting. Yoga is considered to be low cost, simple, nonpharmacological, less exhausting as compared, and popular behavioral intervention that can lower blood pressure in pre-hypertensive HIVinfected adults [20].

A recent study on yoga therapy along with standard treatment for 12 weeks improved quality of life and attenuated the diabetes risk among Indian pre-diabetics and diabetics compared to standard treatment alone[22]. Participants noticed positive impact on their daily routine activities with yoga, gateway activity for sedentary individuals who may shy from standard western exercise regimens [21,23]. Positive effects of yoga with increased mindfulness, greater improvements in diabetes self-care, quality of life, and emotional distress were seen among yoga participants than among standard exercise participants with diabetes $[24,26]$. For reducing pain and increasing satisfaction with pain relief, relaxation, yoga and music may have a role [27].

Table 2: Physical activity of diabetic peripheral neuropathy $(n=70)$ and diabetic non-peripheral neuropathy patients $(n=25)$

Physical activity in diabetic neuropathy patients and diabetic non-neuropathy patients (number of patients, n=70, \%)

\begin{tabular}{llll}
\hline Groups & Physical activity & $\begin{array}{l}\text { Physical activity in diabetic neuropathy } \\
\text { patients (no. of patients, n=70, \%) }\end{array}$ & $\begin{array}{l}\text { Physical Activity in diabetic non- neuropathy } \\
\text { patients (no. of patients, n=25, \%) }\end{array}$ \\
\hline Yoga physical activity & Yoga & 12.8 & 8 \\
group & Walk and yoga & 10 & 24 \\
Non-yoga physical & Walk & 67 & 44 \\
activity group & Walk and exercise & 5.7 & - \\
& Gym & 2.85 & 16 \\
No activity & Gym and yoga & 1.42 & -8 \\
\hline
\end{tabular}

Physical activity in diabetic neuropathy patients and diabetic non- neuropathy patients, $\mathrm{n}=70$ (time=in $\mathrm{min}$ )

\begin{tabular}{|c|c|c|}
\hline $15 \mathrm{~min}$ & 7.14 & 20 \\
\hline $20 \mathrm{~min}$ & $4.28-31.4$ & - \\
\hline $25 \mathrm{~min}$ & 14.28 & 28 \\
\hline $30 \mathrm{~min}$ & 22.85 & 12 \\
\hline $45 \mathrm{~min}$ & 4.28 & 16 \\
\hline $60 \mathrm{~min}$ & 10 & 24 \\
\hline $75 \mathrm{~min}$ & 5.71 & - \\
\hline $90 \mathrm{~min}$ & & - \\
\hline $120 \mathrm{~min}$ & & - \\
\hline
\end{tabular}


Table 3: Comparison of times of yoga and non-yoga physical activities

\begin{tabular}{lll}
\hline Group & Group one & Group two \\
\hline Mean & 47.81 & 49.72 \\
SD & 21.13 & 27.77 \\
SEM & 5.28 & 3.78 \\
N & 16 & 54 \\
\hline
\end{tabular}

Table 4: Comparison of two groups doing yoga physical activity group versus non-yoga physical activity group

\begin{tabular}{lll}
\hline Group & Group 1 & Group 2 \\
\hline Mean & 3.31 & 3.37 \\
SD & 3.55 & 3.22 \\
SEM & 0.89 & 0.44 \\
N & 16 & 54 \\
\hline
\end{tabular}

Thus, physical activity and some sort of physical activity or exercises should be recommended and prescribed to all individuals with diabetes as part of management of glycemic control and overall health.

Very low-quality evidence suggests that yoga might be as effective as other exercise interventions and might be used as an alternative to other exercise programs [25]. These results are in consistence with the present study where no such positive effects were seen with the use of yoga in DPN. One major limitation of the study is that this is the crosssectional analysis of pain scores with a lack of baseline pain scores and follow-up.

\section{Study limitations}

The present study is not without limitations. Inherent limitations of cross-sectional studies are well recognized and appreciated. The sample could have inherent bias like which happens in an open-label study design. Since this the qualitative study aimed to screen patient with diabetic neuropathy attending diabetic clinic of a tertiary care hospital in the capital of India, some form of randomness could naturally be assigned as patients in such a tertiary care clinic in India, which come from the different parts of the city or town, in which they are located. Moreover, there is no particular pattern of patients attending the clinic and they could randomly walk-in on any days of the week as outpatient department runs 7 days a week, 365 days a year. This naturally minimizes the sampling bias, but it cannot rule it out totally.

\section{CONCLUSION}

This implies that those with peripheral neuropathy are as likely to accept yoga as compared to patients with other chronic illnesses practicing non-yoga physical activities.

\section{REFERENCES}

1. Galantino ML, Tiger R, Brooks J, Jang S, Wilson K. Impact of somatic yoga and meditation on fall risk, function, and quality of life for chemotherapy-induced peripheral neuropathy syndrome in cancer survivors. Integr Cancer Ther 2019;18:1

2. Roy V, Gupta M, Ghosh RK. Perception, attitude and usage of complementary and alternative medicine among doctors and patients in a tertiary care hospital in India. Indian J Pharmacol 2015;47:137-42.

3. Kumar D, Goel NK, Pandey AK, Sarpal SS. Complementary and alternative medicine use among the cancer patients in Northern India. South Asian J Cancer 2016;5:8-11.

4. Raveendran AV, Deshpandae A, Joshi SR. Therapeutic role of yoga in Type 2 diabetes. Endocrinol Metab (Seoul) 2018;33:307-17.

5. Thangasami S, Chandani A. Emphasis of yoga in the management of diabetes. J Diabetes Metab 2015;6:1-11.

6. Innes KE, Selfe TK. Yoga for adults with Type 2 diabetes: A systematic review of controlled trials. J Diabetes Res 2016;2016:6979370.

7. Blair SN. Physical inactivity: The biggest public health problem of the $21^{\text {st }}$ century. Br J Sports Med 2009;43:1-2

8. Wu Y, Ding Y, Tanaka Y, Zhang W. Risk factors contributing to Type 2 diabetes and recent advances in the treatment and prevention. Int J Med Sci 2014;11:1185-200.

9. Hemmingsen B, Gimenez-Perez G, Mauricio D, Figuls MR Metzendorf MI, Richter B. Diet, physical activity or both for prevention or delay of Type 2 diabetes mellitus and its associated complications in people at increased risk of developing Type 2 diabetes mellitus. Cochrane Database Syst Rev 2017;12:CD003054.

10. Yates T, Davies M, Gorely T, Bull F, Khunti K. Effectiveness of a pragmatic education program designed to promote walking activity in individuals with impaired glucose tolerance. Diabetes Care 2009;32:1404-10.

11. LaMonte MJ, Blair SN, Church TS. Physical activity and diabetes prevention. J Appl Physiol (1985) 2005;99:1205-13.

12. Bassuk SS, Manson JA. Epidemiological evidence for the role of physical activity in reducing risk of Type 2 diabetes and cardiovascular disease. J Appl Physiol (1985) 2005;99:1193-204.

13. World Health Organization. COVID-19 Significantly Impacts Health Services for Non-Communicable Diseases; 2020. Available from: https://www.who.int/news-room/detail/01-06-2020-covid-19significantly-impacts-health-services-for-noncommunicable-diseases.

14. Nagarathna R, Tyagi R, Kaur G, Vendan V, Acharya IN, Anand A, et al. Efficacy of a validated yoga protocol on dyslipidemia in diabetes patients: NMB-2017 India trial. Medicines (Basel) 2019;6:100.

15. Hung ES, Chen SC, Chang FC, Shiao Y, Peng CW, Lai CH. Effects of interactive video game-based exercise on balance in diabetic patients with peripheral neuropathy: An open-level, crossover pilot study. Evid Based Complement Alternat Med 2019;2019:4540709.

16. Cui J, Yan JH, Yan LM, Pan L, Le JJ, Guo YZ. Effects of yoga in adults with Type 2 diabetes mellitus: A meta-analysis. J Diabetes Investig 2017;8:201-9.

17. Aljasir B, Bryson M, Al-shehri B. Yoga practice for the management of Type II diabetes mellitus in adults: A systematic review. Evid Based Complement Alternat Med 2010;7:399-408.

18. Colberg SR, Sigal RJ, Fernhall B, Regensteiner JG, Blissmer BJ, Rubin RR, et al. Exercise and Type 2 diabetes. Diabetes Care 2010;33:e147-67.

19. Chimkode SM, Kumaran SD, Kanhere VV, Shivanna R. Effect of yoga on blood glucose levels in patients with Type 2 diabetes mellitus. J Clin Diagn Res 2015;9:CC01-3.

20. Cade T, Reeds DN, Mondy KE, Overton T, Grassino J, Tucker S, et al. Yoga lifestyle intervention reduces blood pressure in HIV-infected adults with cardiovascular disease risk factors. HIV Med 2010;11:379-88.

21. Thind H, Guthrie KM, Horowitz S, Conrad M, Bocke BC. I can do almost anything: The experience of adults with Type 2 diabetes with a yoga intervention. Complement Ther Clin Pract 2019;34:116-22.

22. Keerthi GS, Pal P, Pal GK, Sahoo JP, Sridhar MG, Balachander J. Effect of 12 weeks of yoga therapy on quality of life and Indian diabetes risk score in normotensive Indian Young adult prediabetics and diabetics: Randomized control trial. J Clin Diagn Res 2017;11:CC10-4.

23. Colberg SR, Sigal RJ, Yardley JE, Riddell MC, Dunstan DW, Dempsey PC, et al. Physical activity/exercise and diabetes: A position statement of the American diabetes association. Diabetes Care 2016;39:2065-79

24. Schmid AA, van puymbroeck M, Fruhauf CA, Bair MJ, Portz JD. Yoga improves occupational performance, depression, and daily activities for people with chronic pain. Work 2019;63:181-9.

25. Cramer H, Lauche R, Klose P, Lange S, Langhorst J, Dobos GJ. Yoga for improving health-related quality of life, mental health and cancerrelated symptoms in women diagnosed with breast cancer. Cochrane Database Syst Rev 2017;1:CD010802.

26. Bock BC, Thind H, Fava JL, Dunsiger S, Guthrie KM, Stroud L, et al. Feasibility of yoga as a complementary therapy for patients with Type 2 diabetes: The healthy active and in control (HA1C) study. Complement Ther Med 2019;42:125-31.

27. Smith CA, Levett KM, Collins CT, Armour M, Dahlen HG, Suganuma M. Relaxation techniques for pain management in labour. Cochrane Database Syst Rev 2018;3:CD009514. 